\title{
Changes in the Motility Pattern of Human Spermatozoa during In Vitro Incubation
}

\author{
Kazuhiko Hoshi, Kaoru Yanagida, Tomiko Aita, \\ Nobuhiro Yoshimatsu and Akira Sato \\ Department of Obstetrics and Gynecology, Fukushima \\ Medical College, Fukushima 960-12
}

\begin{abstract}
Hoshi, K., Yanagida, K., Aita, T., Yoshimatsu, N. and Sato, A. Changes in the Motility Pattern of Human Spermatozoa during In Vitro Incubation. Tohoku J. exp. Med., 1988, 154 (1), 47-56_- Suspensions of capacitating human spermatozoa were analyzed for movement characteristics using high-speed videomicrography. The status of the acrosome reaction was also assessed by the zona-free hamster ova penetration test. (1) Movement characteristics of human spermatozoa were classified into 4 types (A, B, C, D). Type A : The movement was active, but its progressive orientation was irregular. Type B: The spermatozoa moved with a wide amplitude of the end of tail. Type $\mathrm{C}$ : The amplitude of the tail decreased, and the linear velocity of progression increased. Type D: The whole part of tail showed wavelike rhythmical movements, and the velocity more increased. (2) Movement characteristics of human spermatozoa in vitro gradually changed from Type A to B, C and D. As the spermatozoa classified Type D moved very powerfully and this motility pattern was obviously different from the other types, it was considered hyperactivation of human spermatozoa. The Type D was found from 2 or $3 \mathrm{hr}$ of incubation, and after 3 or $4 \mathrm{hr}$ most of the spermatozoa showed Type D. (3) The motility pattern of human spermatozoa changed to the Type D before the spermatozoa penetrate into zona-free hamster oocytes. It suggested that the hyperactivation occurred before the acrosome reaction takes place. - hyperactivation ; human sperm ; sperm motility; acrosome reaction
\end{abstract}

Sperm motility is required for fertilization in mammals. Adequate motility is necessary not only for spermatozoa to ascend the female reproductive tract and reach the site of fertilization (Mortimer and Templeton 1982 ; Schats et al. 1984), but also for spermatozoa to pass through the egg vestments (the cumulus oophorus and zona pellucida) (Yanagimachi 1970; Bedford 1971; Aitken et al. 1982).

In 1970, Yanagimachi found that the flagellar movements of hamster spermatozoa became extremely active at the time that hamster spermatozoa completed capacitation and began to show evidence of the acrosome reaction. This highcurvature and sometimes thrashing motility was named hyperactivation (Yanagimachi 1970, 1981). Since that first report, similar phenomena have been

Received October 7, 1987 ; revision accepted for publication December 11, 1987. 
observed in capacitated spermatozoa of the guinea pig (Yanagimachi 1972; Barros et al. 1973 ; Yanagimachi and Usui 1974), mouse (Phillips 1972 ; Fraser 1977), dog (Mahi and Yanagimachi 1976), rabbit (Cooper et al. 1979 ; Johnson et al. 1981), bat (Lambert 1981), dolphin (Fleming et al. 1982) and sheep (Cummins 1982 ) as well. The occurrence of hyperactivation in human spermatozoa has been more difficult to study, since the acrosome reaction cannot be directly assessed, capacitation must be carried out in vitro and homologous fertilization cannot be studied experimentally. In recent years, however, the detailed movement characteristics of human spermatozoa have been examined in semen and during capacitation using several new objective methods : cinematography (David et al. 1981), videomicrography (Katz and Overstreet 1981; Burkman 1984; Okada et al. 1985), time-exposure photomicrography (Overstreet et al. 1979; Aitken et al. 1982, 1985) or multiple methods (Mortimer and Templeton 1982). In this report, we show that human spermatozoa change their motility pattern and exhibit hyperactivation when examined between $15 \mathrm{~min}$ and $5 \mathrm{hr}$ of capacitation. Increases in hyperactivated motility were also associated with an increased ability for sperm to penetrate zona-free hamster eggs.

\section{Materials and Methods}

Semen samples were collected by masturbation from proven fertile, healthy donors and allowed to stand at room temperature until liquefaction was completed. Five donors were studied.

Two milliliters of modified Biggers, Whitten and Whittingham medium (mBWW) (Biggers et al. 1971) were added to a small test tube (15 mm in diameter) and $1.0 \mathrm{ml}$ of liquefied semen was then gently introduced to the bottom of the tube (under layering method). The mouth of the test tube was covered with Parafilm; the tube was angled at $30^{\circ}$ and kept at $37^{\circ} \mathrm{C}$ in a $\mathrm{CO}_{2}$ incubator $\left(5 \% \mathrm{CO}_{2}\right.$ in air). In this way, spermatozoa with good motility swam up from the semen into mBWW (Hoshi et al. 1983). Seminal plasma

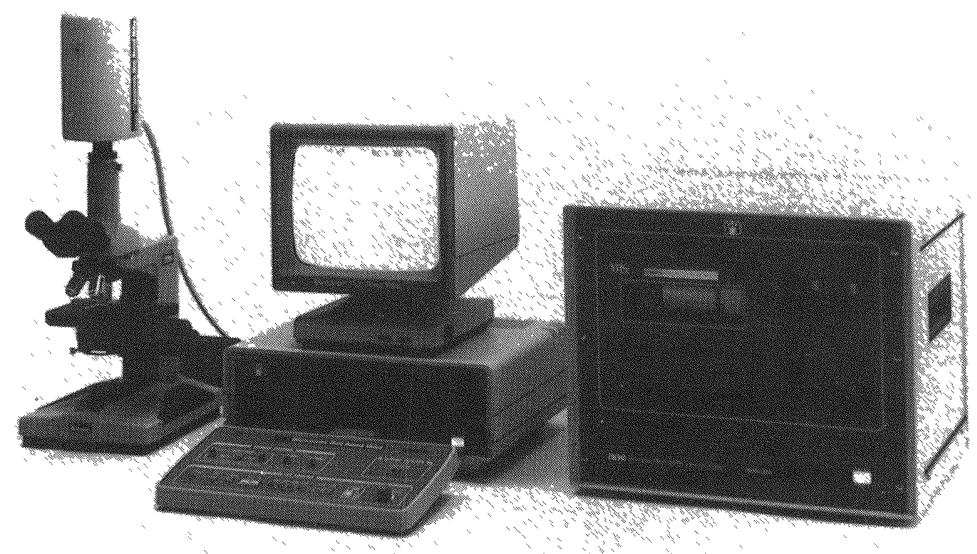

Fig. 1. Microscopic high speed video. 


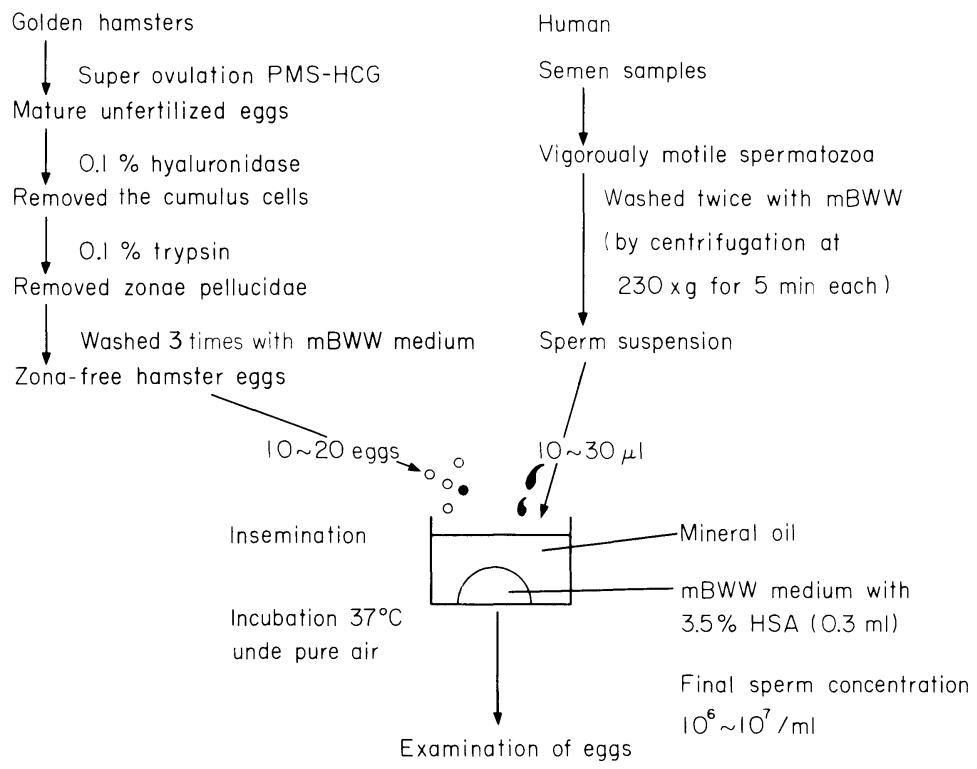

Fig. 2. Outline of hamster test.

A hamster was recorded as "penetrated" when at least 1 swollen sperm head or sperm pronucleus with accompanying sperm tail was discernible within the egg cytoplasm.

at the bottom of the test tube was removed after $1 \mathrm{hr}$. The swim-up sperm in the $\mathrm{mBWW}$ were not washed further and incubation was continued through $5 \mathrm{hr}$.

At specific times after initiation of the layering method (15, $30 \mathrm{~min}, 1,2,3,4,5 \mathrm{hr})$ one drop of the upper mBWW layer was removed and placed directly into a Makler counting chamber (SEFI-Medical Instruments, Haifa, Israel) and the movement of spermatozoa in mBWW was observed as described below. The loaded chamber was placed immediately on the stage of a phase contrast microscope (Nikon XF-ph 21, Nihon Kogaku, Tokyo) and examined at room temperature. The movement of spermatozoa within 10-100 visual fields per sample was recorded by high speed videomicrography (200 frames per sec; Nac Microscopic High Speed Video, NAC, Tokyo ; Fig. 1) for 3 sec. Each recorded frame thus captured the movement of spermatozoa during an interval lasting 5 msec. All videotapes were later analyzed during slow-motion or frame by frame play back. For each sperm, tracings were made of the head and tail positions during the one sec. Four movement types were identified and sperm were classified according to the four patterns. Changes in the distribution of sperm between the 4 patterns was followed during the $5 \mathrm{hr}$ of capacitation.

The straight-line swimming velocity was also calculated for 10 sperms having each motility pattern.

For the purpose of evaluating the completion of capacitation and the acrosome reaction of human spermatozoa, a zona-free hamster ova penetration test (hamster test) was also carried out using the protocol illustrated in Fig. 2.

\section{Results}

In Fig. 3, the consecutive positions of a sperm representing each of the 4 motility patterns are shown (tracings were made every $1 / 40 \mathrm{sec}=25 \mathrm{msec}$ ). Type 
Type A

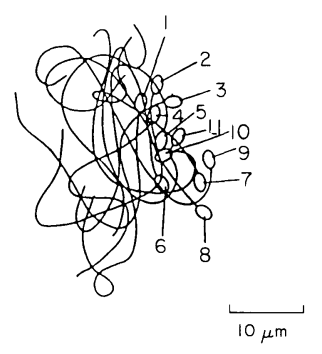

Type C

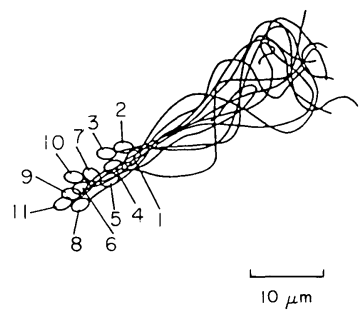

Type B

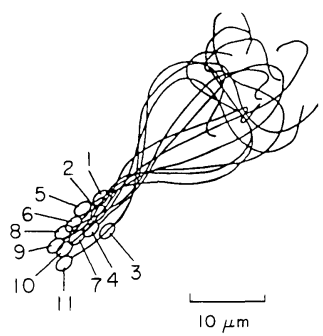

Type D

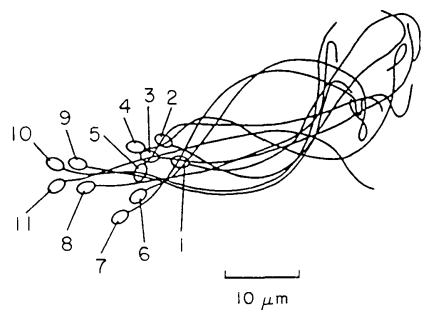

Fig. 3. Classification of movement characteristics of human spermatozoa (25 msec).

Type A : The movement is active but its progressive orientation is irregular. Type B: The spermatozoa move with a wide-amplitude of the end of flagellum.

Type C: The amplitude of flagellar movement decreases, and the linear velocity of progression increases.

Type D: The entire flagellum shows wave-like rhythmical movements, and the velocity more increased.

A sperms had active flagellar movement but were nonprogressive, with errotic head and tail orientations. The head could show great lateral displasement on occasion. Type B and Type $\mathrm{C}$ sperms showed minimal lateral head displacement. Whereas Type B sperms showed the greatest bending of the flagellum in the distal part of the tail, Type $\mathrm{C}$ sperms had increased curvature in the proximal flagellum. Type D sperms had much lateral displacement of the head and could show high curvature of the proximal and distal portions of the tail. The mean straight-line velocity of various types of each case are shown in Table 1.

For each donor Fig. 4 shows how the proportion for each type of sperm movement changes with the lapse of time. As they swim up from semen into the culture medium, spermatozoa show a very disorderly but active movement (Type A). Few spermatozoa move straight at this point in time. Thereafter, spermatozoa that move straight increase in number (Type B). However, these sperms swim with relatively low velocity (Table 1). During the early times, Type A and Type B are very predominant. After 1-2 hr, typically, some sperms appear with 
Case I

$0 \quad 102030405060708090100$

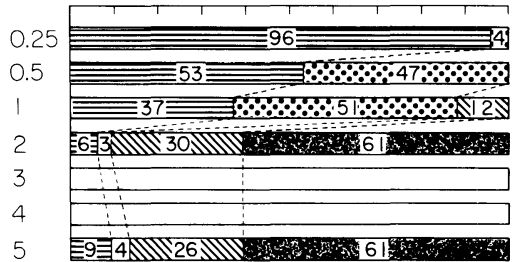

Case 3

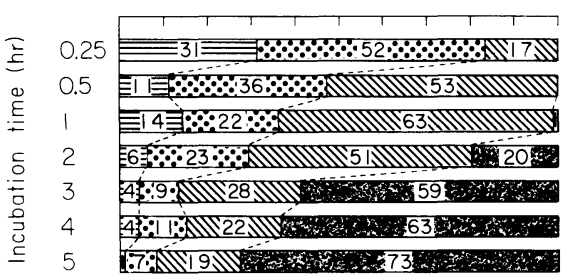

Case 5

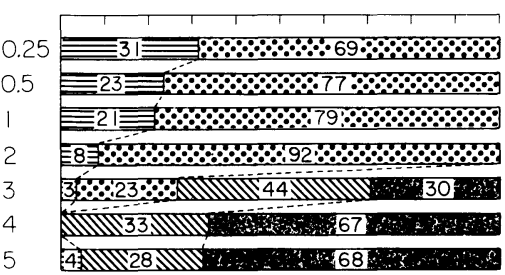

Fig. 4. The proportion of each type changed with the lapse of time.
Case 2

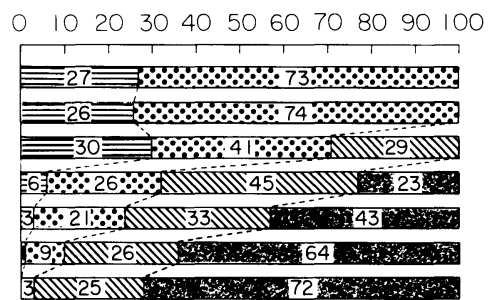

Case 4

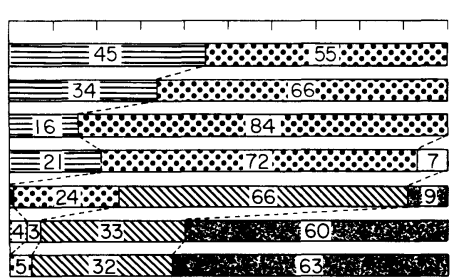

$\Longrightarrow A$

$B$

$C$

D 0

TABLE 1. The mean straight-line velocity for each of the four motility patterns

\begin{tabular}{ccccc}
\hline \multirow{2}{*}{ Case } & \multicolumn{5}{c}{ Type } \\
\cline { 2 - 5 } & $\mathrm{A}$ & $\mathrm{B}$ & $\mathrm{C}$ & $\mathrm{D}$ \\
\hline 1 & $20.1 \pm 7.6$ & $31.4 \pm 8.2$ & $38.9 \pm 7.4$ & $52.3 \pm 7.5$ \\
\hline 2 & $19.3 \pm 9.6$ & $38.8 \pm 6.3$ & $53.0 \pm 10.3$ & $59.5 \pm 8.3$ \\
\hline 3 & $17.1 \pm 4.6$ & $29.5 \pm 4.0$ & $56.4 \pm 7.1$ & $64.1 \pm 10.0$ \\
\hline 4 & $13.9 \pm 7.3$ & $28.7 \pm 9.3$ & $46.2 \pm 7.9$ & $51.7 \pm 4.6$ \\
\hline 5 & $27.4 \pm 8.1$ & $41.2 \pm 11.3$ & $62.7 \pm 11.5$ & $66.3 \pm 10.7$ \\
\hline
\end{tabular}

(Values are means \pm s.D. in $\mu \mathrm{m} / \mathrm{sec}, n=10$ ).

flagellar movements which are regular and smooth (Type C), and which exhibit increased velocity (Table 1). Eventually, a new motility pattern appears and may increase with time (Type D), in which the sperm move ahead at high speed and shake the entire tail in a manner similar to Yanagimachi's description of "whiplash" motility (Yanagimachi 1970). These sperms show a continuous large 
TABLE 2. The results of the hamster test

\begin{tabular}{|c|c|c|c|c|}
\hline Case & $\begin{array}{l}\text { Sperm preincubation } \\
\text { time (hrg) }\end{array}$ & $\begin{array}{l}\text { Number of eggs } \\
\text { inseminated }\end{array}$ & $\begin{array}{l}\text { Number of eggs } \\
\text { penetrated }\end{array}$ & $\begin{array}{l}\% \text { of eggs } \\
\text { penetrated }\end{array}$ \\
\hline \multirow[t]{5}{*}{1} & 2 & 15 & 0 & 0 \\
\hline & 5 & 8 & 1 & 13 \\
\hline & 7 & 14 & 5 & 36 \\
\hline & 9 & 13 & 6 & 46 \\
\hline & 11 & 8 & 6 & 75 \\
\hline \multirow[t]{5}{*}{2} & 5 & 9 & 0 & 0 \\
\hline & 6 & 18 & 6 & 33 \\
\hline & 7 & 8 & 3 & 38 \\
\hline & 8 & 17 & 8 & 47 \\
\hline & 10 & 12 & 8 & 67 \\
\hline \multirow[t]{4}{*}{3} & 5 & 15 & 1 & 7 \\
\hline & 7 & 18 & 6 & 33 \\
\hline & 9 & 17 & 10 & 59 \\
\hline & 11 & 16 & 11 & 69 \\
\hline \multirow[t]{2}{*}{4} & 8 & 25 & 1 & 4 \\
\hline & 10 & 21 & 15 & 71 \\
\hline \multirow[t]{3}{*}{5} & 5 & 7 & 0 & 0 \\
\hline & 6 & 9 & 2 & 22 \\
\hline & 7 & 12 & 10 & 83 \\
\hline
\end{tabular}

lateral displacement of the head (Fig. 3).

The 5 donors showed considerable individual variation in the time course of capacitation as assessed by the hamster assay (Table 2). The duration of sperm incubation required before hamster egg penetration could be achieved varied from 5 to $8 \mathrm{hr}$. A penetration rate of $\geqq 60 \%$ was eventually observed after sperm preincubations of 7 to $11 \mathrm{hr}$, varying with the donor.

For these 5 same studies, as shown in Fig. 5, detectable levels of Type D hyperactivated movements were not seen until 2 or $3 \mathrm{hr}$ of incubation. The levels of Type D did not exceed $50 \%$ until $2-4 \mathrm{hr}$, depending on the donor. We particularly noted that there was a considerable lag between the time when Type $\mathrm{D}$ motility exceeded $50 \%$ and the time when the hamster penetration rate was above $10 \%$. Specifically, that lag time was $3,2,3,5-6$ and $2 \mathrm{hr}$, respectively, for donors 1 through 5 .

\section{Discussion}

Several laboratories have examined the swimming characteristics of human sperm during capacitation. Aitken et al. (1985) analyzed the movement characteristics of pre-incubated human spermatozoa by time-exposure photomicrography 

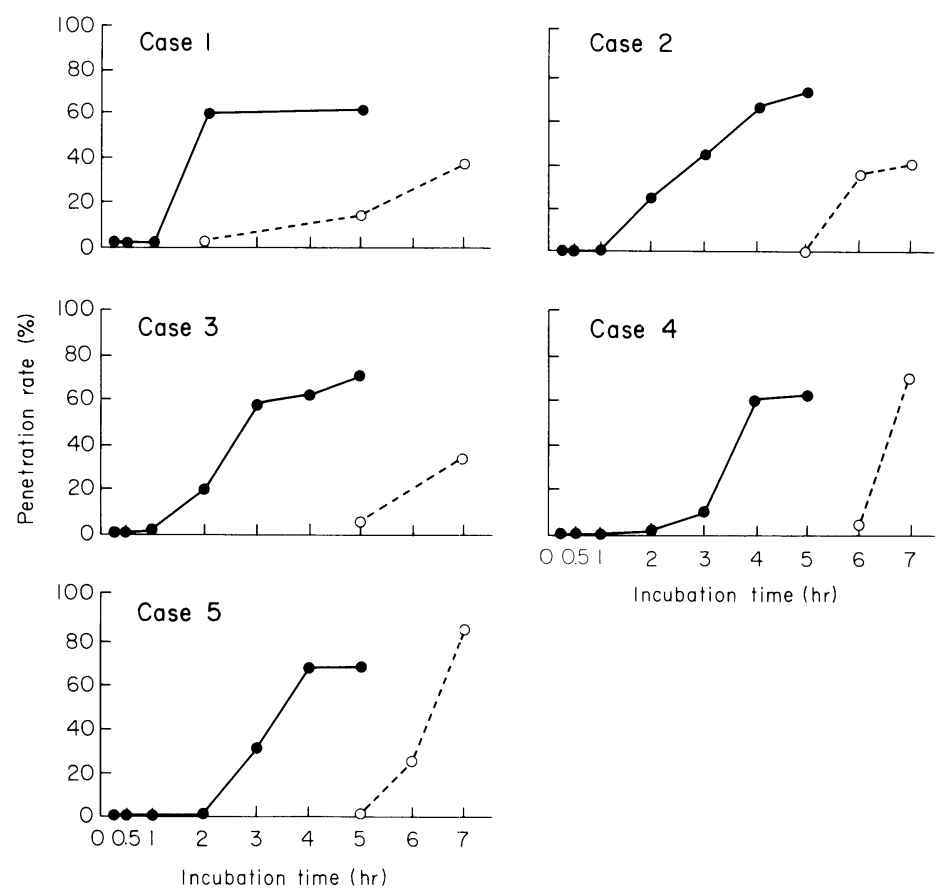

Fig. 5. The penetration rate of hamster test and the percentage of Type D.

as to the linear velocity of progression, frequency of rotation and amplitude of sperm head dislocation. As a result, they reported that the movement characteristics of spermatozoa were significantly lower for the patient group with unexplained infertility compare to the control group, and that there was a close relationship between the quality of seminal sperm movement ability to penetrate cervical mucus. Using a videomicroscopic method, Burkman (1984) defined the hyperactivation of human spermatozoa as one of three basic movement patterns named wide-amplitude, thrashing and star-spin. Using Ham's F10 medium, 80\% of the hyperactivated sperm were "wide-amplitude" with a "two-dimentional whiplash pattern" and "displaying marked lateral displacement of the head". An average of $22.1 \%$ of the fertile spermatozoa displayed motility patterns designated as hyperactivated after approximately $3 \mathrm{hr}$ of incubation, however, only $8.4 \%$ of capacitating spermatozoa from oligozoospermic patients showed these hyperactivated movements. Using the sperm motile efficiency index (SMEI) from Mitsukawa (1979), which shows the proportion of linear progressive spermatozoa, Okada et al. (1985) performed studies comparing fertile and infertile men. They reported that the SMEI values for sperm from fertile men showed significant increases in all the cases after incubation for $4 \mathrm{hr}$. In contrast, sperm from infertile men showed an increased SMEI in only $64 \%$ of the cases. However, in the Okada study it was difficult to correlate SMEI with possible hyper- 
activation.

Previously, we examined changes in the motility rate and velocity of human spermatozoa in culture medium on a timecourse basis using multiple exposure photography (Makler 1978) and found no significant difference between the values at the start of incubation and after $4 \mathrm{hr}$ (Hoshi 1984). However, we did report that the pattern of sperm movement may change with the lapse of time. Burkman (1986) reported on the increase and then decline of total hyperactivation with time, but did not follow individual motility patterns. In this new study, using high speed videomicrography, we have followed the changes in movement characteristics for human spermatozoa over time, and have been able to give details on the successive motility patterns which develop during incubation. At first, spermatozoa which have left the seminal plasma and appeared in the culture medium show very irregular behavior (Type A) but gradually acquire a straight swimming pattern (Type B). For Type B sperm, the beating of the tail dose not serve as an effective driving force and velocities are relatively low ; but, gradually, Type $\mathrm{B}$ appears to transition into Type $\mathrm{C}$, now having a smooth movement and higher velocity.

The present findings suggests that the movement of spermatozoa in culture medium successively changes from Type A to Type D, and the velocity increases accordingly (Table 1). However, it is clear that all the spermatozoa do not change simultaneously, the sperm population is always heterogeneous, with changing proportions of Type A through D. That is probably why there is no detectable change in the mean velocity, even after the lapse of several hours.

Type $\mathrm{D}$ is distinctly different from the other movement types which we have observed in that it shows high velocity and vigorous movement (Fig. 3). While no difinite conclusions can be stated, a change to Type D might be regarded as hyperactivation of human spermatozoa, based on the increased flagellar amplitude and increased lateral head displacement. Type D presents itself $2-3 \mathrm{hr}$ after start of incubation in mBWW medium, and accounts for the majority of all sperm after $3-4 \mathrm{hr}$. The relationship between this putative hyperactivation and the acrosome reaction was examined by use of the hamster penetration test. The penetration rate was zero or low even after $3-5 \mathrm{hr}$ of sperm preincubation, despite the fact that a majority of the spermatozoa were already hyperactivated (Type D). In the human, hyperactivation may occur considerably before the acrosome reaction takes place. Our data may be consistent with the findings of Neill and OldsClarke (1987), where the mechanisms for hyperactivation and the acrosome reaction appear to be separated.

Semen analysis in typically used in diagnosing male fertilizing capacity. As is often experienced clinically, however, results of this analysis are not necessarily consistent with the in vivo or in vitro fertilizing ability. Thus, new methods for examining the function of spermatozoa have gradually appeared and better reflect the true fertilizing capacity. For instance, the zona-free hamster oocyte penetra- 
tion test (hamster test) (Yanagimachi et al. 1976), the triple-stain technique to assess acrosomes (Talbot and Chacon 1981) and penetration of the zona pellucida from non living human oocytes (Overstreet and Hembree 1976; Overstreet et al. 1980) may be mentioned. The gradual acquisition of hyperactivation during capacitation, as shown in this study, is also presumed to be closely related to the fertilizing capacity of spermatozoa.

\section{References}

1) Aitken, R.J., Best, F.S.M., Richardson, D.W., Djahanbakhch, O., Mortimer, D., Templeton, A.A. \& Lees, M.M. (1982) An analysis of sperm function in cases of unexplained infertility: Conventional criteria, movement characteristics, and fertilizing capacity. Fertil. Steril., 38, 212-221.

2) Aitken, R.J., Sutton, M., Warner, P. \& Richardson, D.W. (1985) Relationship between the movement characteristics of human spermatazoa and their ability to penetrate cervical mucus and zona-free hamster oocytes. J. Reprod. Fertil., 73, 441449.

3) Barros, C., Berrios, M. \& Herrera, E. (1973) Capacitation in vitro of guinea pig spermatozoa in a saline solution. J. Reprod. Fertil., 34, 547-549.

4) Bedford, J.M. (1971) Significance of the need for sperm capacitation before fertilization in eutherian mammals. Biol. Reprod., 28, 108-120.

5) Biggers, J.D., Whitten, W.K. \& Whittingham, D.G. (1971) The culture of mouse embryos in vitro. In: Methods in Mammalian Embryology, edited by J.C. Daniel, Jr., W.H. Freeman and Co., San Francisco, p. 86.

6) Burkman, L.J. (1984) Characterization of hyperactivated motility by human spermatozoa during capacitation: Comparison of fertile and oligozoospermic sperm populations. Arch. Androl., 13, 153-165.

7) Burkman, L.J. (1986) Temporal pattern of hyperactivation-like motility in human spermatozoa. Biol. Reprod., 34, Suppl. 1, 226.

8) Cooper, G.W., Overstreet, J.W. \& Katz, D.F. (1979) The motility of rabbit spermatozoa recovered from the female reproductive tract. Gamete Res., 2, 35-42.

9) Cummins, J.M. (1982) Hyperactivated motility patterns of ram spermatozoa recovered from the oviducts of mated ewes. Gamete Res., 6, 53-63.

10) David, G., Serres, C. \& Jouannet, P. (1981) Kinematics of human spermatozoa. Gamete Res., 4, 83-95.

11) Fleming, A.D., Yanagimachi, R. \& Yanagimachi, H. (1982) Spermatozoa of the atlantic bottlenosed dolphin Tursiops truncatus. J. Reprod. Fertil., 63, 509-514.

12) Fraser, L.R. (1977) Motility patterns in mouse spermatozoa before and after capacitation. J. exp. Zool., 202, 439-445.

13) Hoshi, K. (1984) Effects of environmental factors on human fertilization and embryonic development. Acta obstet. gynaec. jap., 36, 1387-1396.

14) Hoshi, K., Nagaike, F., Momono, K., Kyono, K., Tsuiki, A., Saito, A., Suzuki, M., Hayashi, K. \& Yanagimachi, R. (1983) A "layering method" to separate a population of good spermatozoa from semen sample. Jap. J. Fertil. Steril., 28, 101-105.

15) Johnson, L.L., Katz, D.F. \& Overstreet, J.W. (1981) The movement characteristics of rabbit spermatozoa before and after activation. Gamete Res., 4, 275-282.

16) Katz, D.F. \& Overstreet, J.W. (1981) Sperm motility assessment by videomicrography. Fertil. Steril., 35, 188-193.

17) Lambert, H. (1981) Temperature dependence of capacitation in bat sperm monitored by zona-free hamster ova. Gamete Res., 4, 525-533.

18) Mahi, C.A. \& Yanagimachi, R. (1976) Maturation and sperm penetration of canine 
ovarian oocytes in vitro. J. exp. Zool., 196, 189-196.

19) Makler, A. (1978) A new multiple exposure photography method for objective human spermatozoal mortility determination. Fertil. Steril., 30, 192-199.

20) Mitsukawa, S. (1979) A new method for determining sperm motility: The clinical application of sperm motile efficiency. Jap. J. Urol., 70, 1221-1231.

21) Mortimer, D. \& Templeton, A.A. (1982) Sperm transport in the human female reproductive tract in relation to semen analysis characteristics and time of ovulation. J. Reprod. Fertil., 64, 401-408.

22) Neill, J.M. \& Olds-Clarke, P. (1987) A computer-assisted assay for mouse sperm hyperactivation demonstrates that bicarbonate but not bovine serum albumin is required. Gamete Res., 18, 121-140.

23) Okada, A., Kato, M., Fujio, K., Miura, K., Nakayama, K. \& Shirai, M. (1985) Hyperactivation of human spermatozoa: Measurement of motility before and after incubation. Andrologia, 17, 583-586.

24) Overstreet, J.W. \& Hembree, W.C. (1976) Penetration of the zona pellucida of nonliving human oocytes by human spermatozoa in vitro. Fertil. Steril., 27, 815-831.

25) Overstreet, J.W., Katz, D.F., Hanson, F.W. \& Fonseca, J.R. (1979) A simple inexpensive method for objective assessment of human sperm movement characteristics. Fertil. Steril., 31, 162-172.

26) Overstreet, J.W., Yanagimachi, R., Katz, D.F., Hayashi, K. \& Hanson, F.W. (1980) Penetration of human spermatozoa into the human zona pellucida and the zona-free hamster egg: A study of fertile donors and infertile patients. Fertil. Steril., 33, 534542.

27) Phillips, D.W. (1972) Comperative analysis of mammalian sperm motility. J. Cell Biol., 53, 561-573.

28) Schats, R., Aitken, R.J., Templeton, A.A. \& Djahanbakhch, O. (1984) The role of cervical mucus-semen interaction in infertility of unknown aetiology. Brit. $J$. Obstet. Gynaec., 91, 371-376.

29) Talbot, P. \& Chacon, R.S. (1981) A triple-stain technique for evaluating normal acrosome reactions of human sperm. J. exp. Zool., 215, 201-208.

30) Yanagimachi, R. (1970) The movement of golden hamster spermatozoa before and after capacitation. J. Reprod. Fertil., 23, 193-196.

31) Yanagimachi, R. (1972) Fertilization of guinea pig eggs in vitro. Anat. Rec., 174, 9-20.

32) Yanagimachi, R. (1981) Mechanisms of fertilization in mammals. In : Fertilization and Embryonic Development In Vitro, edited by L. Mastroianni \& J.D. Biggers, Plenum, New York, p. 81-182.

33) Yanagimachi, R. \& Usui, N. (1974) Calcium dependence of the acrosome reaction and activation of guinea pig spermatozoa. Exp. Cell Res., 89, 161-174.

34) Yanagimachi, R., Yanagimachi, H. \& Rogers, B.J. (1976) The use of zona-free animal ova as a test-system for the assessment of the fertilizing capacity of human spermatozoa. Biol. Reprod., 15, 471-476. 